\title{
Nature and Roles of Technology in English Language Teaching
}

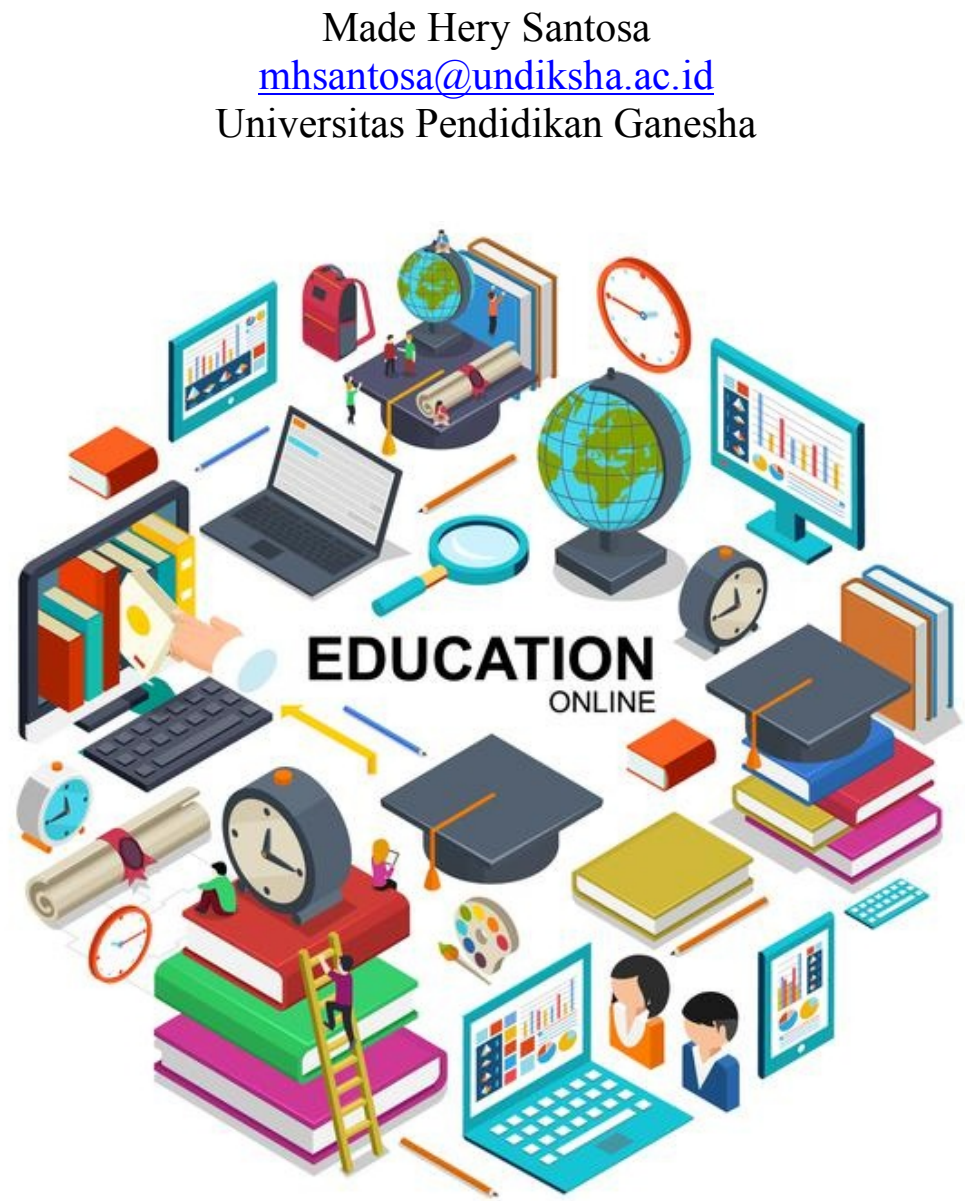

Picture 1. Education Online

Technology has developed throughout the years following the needs of humans. In the language teaching context, technology also develops very rapidly to suit to needs of the instructional process. When computer technology began to be used in the area of language, a well-known term accepted in all circles was Computer Assisted Language Learning (CALL). For decades, there are a number of developing learning support theories, from promoting the environment, such as behaviorism (Behaviorist CALL) to the importance of cognitive abilities with communicative abilities (Communicative CALL), as well as the importance of individual efforts to build their understanding with the integration of various skills (Integrative CALL) (Wulandari \& Pasaribu, 2020). In Behaviorist CALL, technology, especially computers, is used as a medium to help learn English with an emphasis on repetitive language exercises (repetition/drill). The basic principles include an emphasis on repetition as a useful and essential part of learning and direct feedback.

In its later development, Behaviourist CALL received criticism. Just like the theory of Behaviorism, a critique on how students can generate something new from the established 
patterns becomes prominent. Communicative CALL then starts to play a role with the basic principles are a stronger focus on the use of form than on the form itself, implicit grammar teaching, a room for students to produce more sentences from patterns and grammatical formulas, and more exclusive use of the target language in the natural setting.

After some time, the concept of technology-assisted language learning has changed as well. From emphasizing individual and communicative abilities with technology, its development is towards efforts to integrate various language skills with multi-network multimedia technology. This development is termed Integrative CALL, with the basic principles comprising more fully integration of various language learning skills and technology into language teaching and availability of rich information, tools, and intelligent technologies for learning.

As technology develops, the industrial revolution, and global demands, the term CALL begins to shift towards using any media - not just computers - as long as the media helps students understand the material and grows them to be ready in a different context later when they finish school. The term CALL has begun to shift to Technology Enhanced Language Learning (TELL) with the emergence of a wide variety of media technologies and Mobile Assisted Language Learning (MALL) as a variation in response to the rapid growth of smartphones or smartphones and applications, all of which are in our hands and can be used anytime and anywhere only (mobile) (Putra \& Santosa, 2020).

Today, technology is certainly no stranger to all of us. Our students may even be faster in using technology because they are believed to be a generation born with technology (Prensky, 2001). Therefore, to utilize technology most effectively in language teaching, a relevant and strong pedagogic framework is needed to orchestrate all learning components. One of them is the Technology, Pedagogy, and Content Knowledge (TPACK) framework. According to (Mishra \& Koehler, 2006), TPACK is a framework that integrates Technological Knowledge, Pedagogical Knowledge, and Content Knowledge in a learning context. 


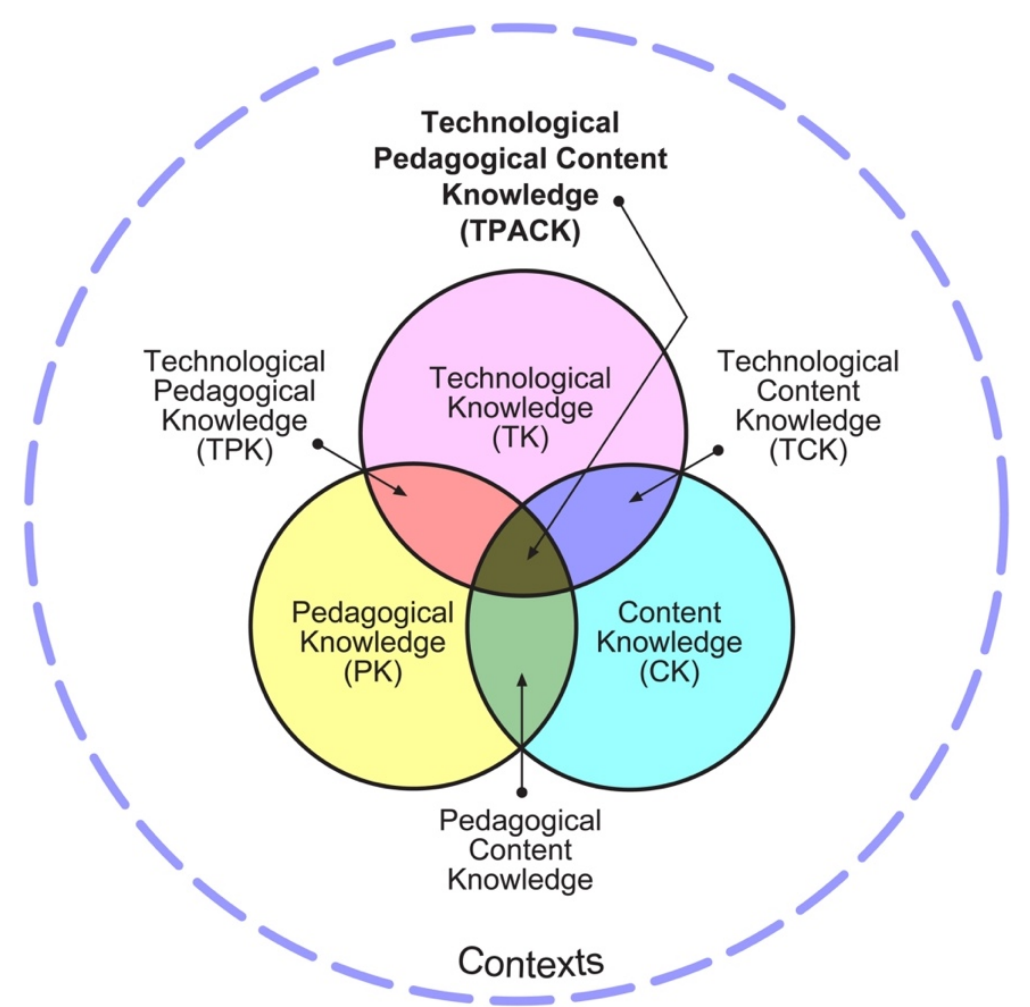

Picture 2. TPACK Framework (Mishra \& Koehler, 2006)

TPACK was originally developed by Shulman (1986) who described Pedagogical and Content Knowledge (PCK). He emphasized that learning success occurs when the teacher understands the content of certain subjects to be taught and how to deliver these subjects. Over time, technology develops very rapidly and by Mishra and Koehler (2006), technology components are included in this framework. Given that these frameworks intersect with each other, there are seven integration variables of the components in the TPACK framework that must be considered.

1. Technological Knowledge (TK) is knowledge of how to operate computers and relevant software;

2. Pedagogical Knowledge (PK) is the ability to manage student learning;

3. Content Knowledge (CK) is the subject matter of knowledge such as knowledge of the language, Mathematics, Natural Sciences, and others;

4. Technological Content Knowledge (TCK) is knowledge about how content can be researched or represented by technology such as using computer simulations to represent and study cultures in various parts of the world with Google Earth;

5. Pedagogical Content Knowledge (PCK) is knowledge about how to convey content or information on a subject understood by others; 
6. Technological Pedagogical Knowledge (TPK) is knowledge about how technology can facilitate pedagogical approaches, for example using asynchronous discussions such as forums to support the social construction of knowledge;

7. Technological Pedagogical Content Knowledge (TPACK) is knowledge about how to facilitate the learning of trainees from certain content through pedagogical and technological approaches.

TPACK describes how technological knowledge can work with PCK to produce effective learning. Context aspects, such as facilities, student abilities, teacher strategies, and others must also be considered in integrating the TPACK framework in learning. TPACK continues to develop from time to time through a series of research and publications. By understanding the relationship between the learning components in the TPACK framework mentioned above, the teacher can find out what factors have the most significant influence on the teaching and learning process in order to improve the quality of professional and ICT-based teachers.

As technology becomes part of language teaching and learning, its roles become more significant. Technologies present benefiting roles in the instructional process of English (Amin, 2019; Hussain \& Safdar, 2008). For students, technologies are believed to assist them to:

1. participate in a media revolution, profoundly affecting the way they think about and use information technologies,

2. improve the ways of learning in new learning fashions,

3. extend the ability and skills of applying their learning in real situations,

4. work in groups for cooperative and collaborative learning,

5. develop self-learning habits at their own pace and time,

6. learn with the teacher rather than by the teacher,

7. develop inquiry-learning habits,

8. use the right information at right time to achieve the right objective,

9. review and explore qualitative data, and

10. exchange learning experiences and information with other students and teachers living anywhere in the world.

In the teaching and learning process in the 21 st century, technologies also enable teachers to:

1. present the material in a more interesting and attractive way,

2. guide and help students in searching the qualitative material,

3. make the best use of time, 
4. coach the students,

5. provide individualized instruction,

6. direct the students toward cooperative as well as collaborative learning activities,

7. prepare learning material for students, rather than teaching in conventional situations,

8. diagnose the learning problem of students and help them to overcome, and

9. solve the study problems of students.

Aside from these benefiting roles, technologies also present challenges in the language teaching process. Some prominent ones involve internet connectivity, gadgets' availability, the readiness of technologies, institutional supports, learning geolocations, and learning styles, approaches, and autonomy using technology (Crossley \& McNamara, 2017; Johnson et al., 2016; Looi et al., 2019; Uden et al., 2017, 2018, 2019; Wiraningsih \& Santosa, 2020).

Technology has been developing rapidly and influencing many fields, including language teaching. In the area of English as a foreign language (EFL), technology has been strongly evolving and taking important roles. An emphasis on content, pedagogy, and technology supports is undeniably important for the success of the teaching and learning process. Successful integration of technology is believed to assist students and teachers more effectively in the instructional process. However, it is also important to note that besides providing benefits to learning, technology must be utilized wisely for it also presents challenges in the learning process.

\section{Additional Material}

To enrich your understanding of the topic, please read the following materials.

1. Wulandari, M., \& Pasaribu, T. A. (2020). Technology for English language learning. Sanata Dharma University Press.

2. Looi, C.-K., Wong, L.-H., Glahn, C., \& Cai, S. (2019). Seamless learning: Perspectives, challenges, and opportunities. In C.-K. Looi, L.-H. Wong, C. Glahn, \& S. Cai (Eds.), Lecture Notes in Educational Technology. Springer. https://doi.org/10.4324/9780429485534-9.\&nbsp;

\section{References}

Amin, M. R. (2019). The role of educational technology in the ESL classroom. Global Journal of Archaelogy \& Anthropology, 11(1), 1-11. https://doi.org/10.5772/intechopen.72887.

Crossley, S., \& McNamara, D. (2017). Adaptive educational technologies for literacy instruction (S. Crossley \& D. McNamara (eds.)). Routledge. https://doi.org/https://doi.org/10.4324/9781315647500. 
Johnson, A. M., Jacovina, M. E., Russell, D. G., \& Soto, C. M. (2016). Challenges and solutions when using technologies in the classroom. In Adaptive educational technologies for literacy instruction (pp. 13-29). Routledge.

Hussain, I., \& Safdar, M. (2008). Role of information technologies in teaching learning process: Perception of the faculty. Turkish Online Journal of Distance Education, 9(2), 46-56. https://doi.org/10.17718/tojde.27416.

Looi, C.-K., Wong, L.-H., Glahn, C., \& Cai, S. (2019). Seamless learning: Perspectives, challenges and opportunities. In C.-K. Looi, L.-H. Wong, C. Glahn, \& S. Cai (Eds.), Lecture Notes in Educational Technology. Springer. https://doi.org/10.4324/9780429485534-9.

Mishra, P., \& Koehler, M. (2006). Technological pedagogical content knowledge: A framework for teacher knowledge. The Teachers College Record, 108(6), 10171054. https://doi.org/10.1111/j.1467-9620.2006.00684.x.

Putra, M. A. M., \& Santosa, M. H. (2020). Mobile assisted language learning in Intensive English Course for freshmen year students. Journal of Educational Technology, 4(2), 127-132. https://doi.org/http://dx.doi.org/10.23887/jet.v4i2.25097.

Prensky, B. M. (2001). Digital Natives , Digital Immigrants. 1-6.

Shulman, L. S. (1986). Those who understand: Knowledge growth in teaching. American Educational Research Association, $\quad$ 15(2), 14. https://doi.org/http://www.jstor.org/stable/1175860.

Uden, L., Liberona, D., \& Liu, Y. (2017). Learning technology for education challenges. In L. Uden, D. Liberona, \& Y. Liu (Eds.), Communications in Computer and Information Science. Springer. https://doi.org/10.1007/978-3-319-62743-4_8.

Uden, L., Liberona, D., \& Ristvej, J. (2018). Learning technology for education challenges. In L. Uden, D. Liberona, \& J. Ristvej (Eds.), Communications in Computer and Information Science. Springer.

Uden, L., Liberona, D., Sanchez, G., \& Rodríguez-González, S. (2019). Learning technology for education Challenges. In L. Uden, D. Liberona, G. Sanchez, \& S. RodríguezGonzález (Eds.), Communications in Computer and Information Science. Springer. https://doi.org/10.1007/978-3-030-20798-4 8.

Wiraningsih, P., \& Santosa, M. H. (2020). EFL teachers' challenges in promoting learner autonomy in the 21 st century learning. Journal on English as a Foreign Language, 10(2), 290-314. https://doi.org/https://doi.org/10.23971/jefl.v10i2.1881.

Wulandari, M., \& Pasaribu, T. A. (2020). Technology for English language learning. Sanata Dharma University Press.

Please cite this source accordingly using an appropriate reference system and manager. 